\title{
Pengelolaan Panen dan Pascapanen Kopi Arabika (Coffea arabica L.) di Kebun Kalisat Jampit, Bondowoso, Jawa Timur
}

\section{Harvest and Post Harvest Management of Arabica Coffee (Coffea arabica L.) at Kalisat Jampit Plantation, Bondowoso, East Java}

\section{Yunna Ega Ash Yokawati dan Ade Wachjar*}

\author{
Departemen Agronomi dan Hortikultura, Fakultas Pertanian, Institut Pertanian Bogor \\ (Bogor Agricultural University), Jl. Meranti, Kampus IPB Darmaga, Bogor 16680, Indonesia \\ Telp.\& Faks.62-251-8629353 e-mail agrohort@apps.ipb.ac.id \\ *Penulis Korespondensi : wachjarade@yahoo.co.id
}

Disetujui : 21 Mei 2018 / Published Online September 2019

\begin{abstract}
The purpose of this research had to analyze and identify the problem that occur in harvesting and post harvesting of Arabica coffee and also to discover the solution for the problem. The research activity is implemented on PT Nusantara Plantation XII, Bondowoso, East Java, in 4 months, starting from February until June 2018. Harvesting preparation in Kalisat Jampit Plantation consists of fruit taxation and harvesting tools preparation. Fruit taxation is three times, by afdeling, plantation, and office directors. The harvesting tools preparations are consist of field preparation, material and tool preparations, and labor preparation. The field area of plantation in every afdeling divides into 12 harvesting blocks. Every harvesting rotation in Kalisat Jampit Plantation consists of 8-12 day. The spacious of harvesting field is determined by the harvesting area and plants conditions. Total amount of labor that is needed in every harvesting activity is calculated according to the quantity of coffee fruit harvest will be dividing with the average of harvester capabilities and total amount of harvesting days. Harvesting activities in Kalisat Jampit Plantation consist of harvesting ripe fruit, yield sorting by harvester, and also weighing yield. The lost rate of yield occurs caused by the fruits that fall on the ground reached a percentage of $73 \%$. The observations result on the influence of the age harvester labor shows the older harvester (41-60) ages achieve a great harvest achievement rather than the younger harvester (20-40) ages. Meanwhile, the harvest achievement based on gender shows the women harvester labor is equal to men harvester. The coffee processing consist of two process, there are wet process $(W P)$ and dry process $(D P)$.
\end{abstract}

Keywords: coffee, criteria of harvesting, harvesting, the lost rate of yield, labor of harvesting

\section{ABSTRAK}

Tujuan penelitan ini yaitu menganalisis dan mengidentifikasi permasalahan yang dihadapi dalam kegiatan panen dan pascapanen kopi Arabika serta mencari solusinya. Kegiatan panen dilaksanakan di Kebun Kalisat Jampit, Kabupaten Bondowoso, Jawa Timur selama 4 bulan mulai Februari hingga Juni 2018. Persiapan panen di Kebun Kalisat Jampit terdiri atas kegiatan taksasi buah kopi dan persiapan sarana panen. Kegiatan taksasi buah kopi dilakukan tiga kali, yaitu oleh afdeling, kebun, dan tim kantor direksi. Sarana panen terdiri atas persiapan areal panen, persiapan alat dan bahan, dan persiapan tenaga kerja. Areal kebun di masing-masing afdeling dibagi menjadi 12 blok petik (panen). Setiap rotasi panen di Kebun Kalisat Jampit selang 8-12 hari. Luas panen ditentukan oleh kondisi areal panen dan kondisi tanaman. Jumlah tenaga kerja yang dibutuhkan pada kegiatan pemanenan dihitung berdasarkan jumlah buah kopi yang akan dipanen dibagi rata-rata kemampuan pemetik memanen dan jumlah hari panen. Kegiatan pemanenan di Kebun Kalisat Jampit terdiri atas pemetikan buah kopi matang, sortasi buah, dan penimbangan buah. Hasil pengamatan menunjukkan bahwa kehilangan hasil panen sebagian besar disebabkan buah yang jatuh di piringan, jumlahnya mencapai $73 \%$ dari jumlah kehilangan hasil. Prestasi pemetik berdasarkan usia menunjukkan bahwa prestasi pemetik berusia 41-60 tahun rata-rata lebih tinggi dibandingkan dengan usia 20-40 tahun. Sementara itu, prestasi tenaga pemetik berdasarkan jenis kelamin menunjukkan bahwa tenaga pemetik perempuan prestasinya sama dengan tenaga pemetik laki-laki. Kegiatan pengolahan kopi dibagi menjadi dua cara, pengolahan kopi secara basah (wet process/WP) dan pengolahan kopi secara kering (dry process/DP).

Kata Kunci: kehilangan hasil, kriteria petik, kopi, panen, pemetik 


\section{PENDAHULUAN}

Kopi termasuk komoditas perkebunan yang banyak diperdagangkan di pasar internasional. Indonesia merupakan negara penghasil kopi terbesar ke empat dunia setelah Brazil, Vietnam, dan Kolumbia (Afriliana, 2018). Sasaran ekspor kopi yang berasal dari Indonesia umumnya ke negara Amerika, Jepang, Belanda, dan Italia (Panggabean, 2011). Perkebunan kopi berdasarkan status pengusahaannya terdiri atas 96\% perkebunan rakyat, $2 \%$ perkebunan swasta, dan $2 \%$ perkebunan negara. Luas areal kebun kopi di Indonesia pada tahun 2011 adalah 1233698 ha dengan produksi 638,646 ton, produktivitas 624.2 $\mathrm{kg} \mathrm{ha}{ }^{-1}$, nilai ekspor yang dihasilkan US\$ 1036.671 juta dari volume ekspor 346493 ton. Luas areal kebun kopi di Indonesia tahun 2015 adalah 1230001 ha dengan produksi 639421 ton, produktivitas $920.69 \mathrm{~kg} \mathrm{ha}^{-1}$, nilai ekspor yang dihasilkan US\$ 1197.735 juta dari volume ekspor 502021 ton (Ditjenbun, 2016). Dibandingkan dengan tahun 2011, pada tahun 2015 terjadi penurunan luas areal, peningkatan produksi, produktivitas, nilai dan volume ekspor.

Dua jenis kopi yang memiliki nilai ekonomis dan diperdagangkan secara komersial terdiri atas kopi Arabika dan kopi Robusta. Permintaan kopi Arabika lebih tinggi dibandingkan dengan kopi Robusta. Bagi penikmat kopi dunia, kopi Arabika memiliki cita rasa yang unggul. Harga kopi Arabika lebih tinggi dibandingkan dengan kopi Robusta. Konsumsi kopi dunia mencapai $70 \%$ berasal dari spesies kopi Arabika dan 26\% berasal dari kopi Robusta. Indonesia hanya dapat memproduksi sekitar $27 \%$ kopi Arabika dan sisanya merupakan kopi Robusta. Rendahnya produksi kopi Arabika disebabkan oleh kopi Arabika hanya bisa tumbuh baik pada dataran tinggi yaitu pada ketinggian $\geq 1$ 000 meter di atas permukaan laut (dpl), sedangkan kopi Robusta dapat tumbuh $\leq 1000 \mathrm{~m}$ dpl. Sebagian besar wilayah Indonesia berada di dataran rendah (Rahardjo, 2012 dan Ditjenbun, 2016).

Produksi kopi yang baik secara kualitas maupun kuantitas salah satunya ditentukan oleh kegiatan panen dan pascapanen. Proses pemanenan yang tepat akan meningkatkan mutu dan jumlah produksi kopi. Kopi yang bermutu tinggi dipetik setelah matang, yaitu saat kulit buah berwarna merah (Najiyati dan Danarti, 2004). Menurut Manurung et al. (2016) yang mempengaruhi jumlah produksi kopi Arabika yaitu luas lahan, pemupukan, aplikasi herbisida, dan tenaga kerja. Menurut Mayrowani (2013) produk hasil perkebunan atau pertanian setelah dipanen masih melakukan aktivitas metabolisme, sehingga jika tidak ditangani dengan segera akan mengakibatkan kerusakan secara fisik dan kimia. Sifat mudah rusak (perishable) dari produk pertanian tersebut mengakibatkan tingginya susut pascapanen serta terbatasnya masa simpan setelah pemanenan, sehingga serangan organisme hama dan penyakit akan menurunkan mutu produk.

Permasalahan panen dan pascapanen yang dihadapi petani kopi Arabika pada umumnya adalah pemetikan buah yang belum matang, fermentasi yang tidak sempurna dan terlalu lama, penjemuran di atas permukaan tanah, kopi berkulit tanduk yang cacat, dan tingkat kadar air yang tinggi (Saragih, 2010). Menurut Sembiring et al. (2015) kualitas dalam memproduksi kopi ditentukan oleh proses pengolahan kopi, umumnya petani lebih memilih proses pengolahan secara kering dengan biaya pengolahan yang lebih rendah dibandingkan dengan proses pengolahan secara basah. Proses pengolahan secara basah menghasilkan kualitas kopi yang lebih baik dibandingkan hasil produksi dari proses pengolahan kering. Menurut Mayrowani (2013) sebagian besar cara pengolahan kopi secara basah dilakukan oleh perkebunan besar, sehingga menghasilkan mutu fisik kopi yang baik, tetapi pada proses fermentasi terdapat resiko kerusakan pada cita rasa. Proses fermentasi sulit diterapkanoleh petani kopi karena membutuhkan biaya produksi yang lebih tinggi dan umumnya teknologi pascapanen yang digunakan petani masih tradisional.Terkait dengan informasi dan permasalahan di atas, maka tulisan ini difokuskan pada pengelolaan panen dan pascapanen kopi Arabika dalam meningkatkan jumlah produksi dan mutu kopi. Tujuan penelitian adalah menganalisis dan mengidentifikasi permasalahan yang dihadapi dalam kegiatan panen dan pascapanen kopi Arabika serta mencari solusinya.

\section{BAHAN DAN METODE}

Kegiatan penelitian dilaksanakan di Kebun Kalisat Jampit, Kecamatan Sempol, Kabupaten Bondowoso, Provinsi Jawa Timur dengan ketinggian 1 050-1 500 mdpl. Penelitian berlangsung selama 4 bulan, mulai bulan Februari sampai Juni 2018.

Pengumpulan data dan informasi dilakukan saat pelaksanaan penelitian. Pengumpulan data meliputi data primer dan data sekunder. Data primer merupakan informasi yang diperoleh dengan cara pengamatan langsung di lapangan, baik pada kegiatan pemeliharaan maupun panen dan pascapanen, serta melalui diskusi dengan karyawan harian lepas (KHL), mandor, dan asisten kebun. Pengamatan difokuskan pada 
kegiatan panen dan pascapanen kopi Arabika dengan peubah yang mempengaruhi produktivitas biji kopi, kualitas/mutu panen dan pasca panen, komposisi buah selama panen hingga pascapanen, dan kebutuhan tenaga kerja. Peubah yang diamati terdiri dari luas areal panen, yang diamati adalah pembagian luas lahan panen. Pengamatan merupakan pengambilan data pembagian rotasi panen dari perusahaan. Tenaga pemanen, yang diamati terdiri atas tenaga pemanen berdasarkan usia dan gender terhadap prestasi panen. Pengamatan pengaruh usia terhadap prestasi panen dilakukan dengan cara menggolongkan pemetik pada usia muda (20-40 tahun) dengan pemetik usia tua (41-60 tahun). Data prestasi para pemetik baik berdasarkan usia maupun gender diambil dari pengamatan penulis di lapangan dengan ulangan 3 kali pada hari panen yang berbeda, dan masing-masing ulangan terdiri atas 10 sampel.

Alat panen yang digunakan, yaitu pengamatan dilakukan dengan pencatatan jenis alat panen yang digunakan dalam proses pemanenan kopi di kebun. Hasilnya dibandingkan dengan standar kebun dan studi pustaka. Kriteria buah kopi yang dapat dipanen, yang dilakukan sebanyak 3 kali ulangan pada hari panen yang berbeda, setiap ulangan terdiri atas 5 sampel tenaga pemetik usia muda (20-40 tahun) dengan 5 sampel tenaga pemetik usia tua (41-60 tahun). Setiap sampel tenaga pemetik usia muda dan usia tua diambil sebanyak $1 \mathrm{~kg}$ buah kopi hasil petik, kemudian buah merah, buah hijau, dan buah kuning (bancuk) dipisahkan lalu dihitung persentase beratnya. Faktor-faktor kehilangan hasil dan tingkat kehilangan hasil (losses) buah pada saat pemanenan.yang merupakan pengamatan penulis selama kegiatan panen di lapangan. Pengamatan tingkat kehilangan hasil dilakukan dengan mengambil sampel sebanyak 10 tanaman per blok. Setiap sampel tanaman dihitung jumlah buah kopi yang jatuh pada gawangan tanaman, dan rendemen kopi yang diperoleh, dengan menghitung rendemen kopi yang dihasilkan, kemudian dibandingkan dengan standar perusahaan dan studi pustaka.

Analisis data penelitian meliputi analisis deskriptif maupun analisis kuantitatif dengan menggunakan ukuran distribusi (frekuensi atau persen), ukuran pemusatan (rata-rata), atau hubungan input-out put (uji student, regresi, korelasi). Hasil tersebut disajikan dalam bentuk tabel/grafik, kemudian diuraikan secara deskriptif dengan membandingkan proses panen dan pascapanen pada perusahaan perkebunan kopi yang kemudian dilakukan juga studi pustaka sebagai pembanding.
Lokasi Kebun Kalisat Jampit terletak di Desa Kalisat, Kecamatan Ijen, Kabupaten Bondowoso, Jawa Timur dengan letak geografis $96.80^{\circ} \mathrm{LS}$ dan $06.60^{\circ} \mathrm{BT}$. Areal kebun tertinggi adalah 1,550 mdpl dan terendah 1,100 mdpl. Kebun Kalisat Jampit bagian timur berbatasan dengan Kebun Blawan, sedangkan bagian utara, selatan dan barat berbatasan langsung dengan areal Perhutani.

Kebun Kalisat Jampit memiliki tipe iklim C-D (menurut Schmidt-Ferguson). Curah hujan rata-rata tahunan 1,667 $\mathrm{mm}$ dengan hari hujan 134 hari serta bulan basah 7 bulan dan bulan kering 5 bulan. Kelembaban udara rata-rata $82 \%$ dengan kelebaban tertinggi $95.70 \%$ dan terendah $57.40 \%$. Rata-rata suhu harian $18{ }^{\circ} \mathrm{C}$ dengan suhu terendah $5{ }^{\circ} \mathrm{C}$ dan suhu tertinggi $40{ }^{\circ} \mathrm{C}$.

Kebun Kalisat Jampit terletak pada dataran tinggi Pegunungan Ijen, tanah yang dipengaruhi letupan gunung merapi, sehingga bentuk tanah berwarna kelabu kelam oleh kadar humus arang (koolhumus) dan unsur-unsur hara yang tinggi, kecuali $\mathrm{Mg}$ yang rendah sampai sedang. Batuan Pegunungan Ijen terdiri atas batuan pyroxeen anderit, bazalt dan sedikit horblende. Bazalt mempunyai kadar asam kresik yang cukup tinggi. Topografi di Kebun Kalisat Jampit bergelombang hingga berbukit dengan kemiringan $30-40 \%$ dan sebagian dengan kemiringan 70-80\% dengan lembah yang curam dan terjal.

Kebun Kalisat Jampit memiliki luas areal Hak Guna Usaha (HGU) 3,105.41 ha. Kebun Kalisat Jampit terdiri atas enam afdeling yaitu lima afdeling kebun dan satu Afdeling Pabrik (6.00 ha). Lima afdeling kebun terdiri atas Afdeling Kampung Baru (402.22 ha), Afdeling Kampung Malang (491.41 ha), Afdeling Sempol (387.94 ha), Afdeling Krepekan (386.68 ha), dan Afdeling Jampit $(1,431.16$ ha). Jenis tanaman yang dibudidayakan adalah Kopi Arabika.

Tanaman kopi Arabika yang terdapat di Kebun Kalisat Jampit terdiri atas beberapa varietas, yaitu Typika, Kate, USDA, Lini S, dan HDT. Jarak tanam yang digunakan $1.75 \mathrm{~m}$ x 1.75 $\mathrm{m}, 1.25 \mathrm{~m} \times 2.50 \mathrm{~m}$, dan $2.50 \mathrm{~m} \times 2.50 \mathrm{~m}$. Luas areal tanaman menghasilkan (TM) adalah 1373.15 ha dengan jumlah tanaman produktif 2 731064 pohon. Rata-rata populasi tanaman sekitar 2000 tanaman ha ${ }^{-1}$.

Tanaman pelindung di Kebun Kalisat Jampit terdiri atas tanaman pelindung tetap dan tanaman pelindung sementara. Tanaman pelindung sementara yang digunakan terdiri atas Mogania (Moghania macrophylla) dan teprosia (Tephrosia sp.). Tanaman pelindung tetap yang digunakan terdiri atas lamtoro (Leucaena glauca Benth) L2 dan lamtoro PG 79. Jarak tanam penaung tetap yang digunakan adalah $5 \mathrm{~m} \mathrm{x} 4 \mathrm{~m}$. 
Tabel 1. Luas areal, produksi, rendemen, dan produktivitas kopi Arabika di Kebun Kalisat Jampit 2013-2017

\begin{tabular}{|c|c|c|c|c|c|}
\hline Tahun & $\begin{array}{l}\text { Luas Areal } \\
\text { (ha) }\end{array}$ & $\begin{array}{l}\text { Produksi Buah } \\
\text { kopi }(\mathrm{kg})\end{array}$ & $\begin{array}{c}\text { Produksi Biji } \\
\text { Kopi Kering }(\mathrm{kg})\end{array}$ & Rendemen $(\%)$ & $\begin{array}{l}\text { Produktivitas Biji Kopi } \\
\text { Kering }(\mathrm{kg} / \mathrm{ha})\end{array}$ \\
\hline 2013 & 1149.56 & 2071540 & 334329 & 16.14 & 291 \\
\hline 2014 & 1280.15 & 6874120 & 1144561 & 16.65 & 894 \\
\hline 2015 & 1344.79 & 4184891 & 673939 & 16.08 & 500 \\
\hline 2016 & 1373.79 & 1968569 & 324247 & 16.45 & 236 \\
\hline 2017 & 1373.79 & 4280741 & 711323 & 16.62 & 518 \\
\hline Rata-rata & 1304.42 & 3875972 & 637480 & 16.39 & 488 \\
\hline
\end{tabular}

Sumber : Kantor Kebun Kalisat Jampit 2018

Tanaman pemecah angin yang digunakan adalah sengon (Albizia falcataria).

Hasil panen dari masing-masing afdeling dikirim ke pabrik pengolahan Kebun Kalisat Jampit untuk diolah menjadi kopi biji kering (green bean). Produksi tanaman kopi di Kebun Kalisat Jampit mengalami fluktuasi dari tahun ke tahun. Hal tersebut disebabkan oleh tanaman kopi memiliki sifat biennial bearing. Rata-rata produksi selama lima tahun terakhir (2013-2017) sebesar $\quad 3875972 \quad \mathrm{~kg}$ glondong yang menghasilkan $637480 \mathrm{~kg}$ biji kering dengan rendemen $16.39 \%$ dan produktivitas $488 \mathrm{~kg} \mathrm{ha}^{-1}$ (Tabel 1)

Tenaga kerja di Kebun Kalisat Jampit, berdasarkan sistem kerjanya digolongkan menjadi karyawan staf (IIIA-IVD) dan non staf (IA-IID). Tenaga staf di Kebun Kalisat Jampit terdiri atas manajer,wakil manajer, asisten tanaman, asisten teknik dan pengolahan, dan asisten administrasi keuangan dan umum. Tenaga kerja non staf di Kebun kalisat Jampit terdiri atas karyawan bulanan tetap (KBT), karyawan harian tetap (KHT), dan karyawan harian lepas (KHL). Jumlah tenaga kerja di Kebun Kalisat Jampit pada bulan Februari 2018 berjumlah 1719 orang. Rasio pekerja per ha di Kebun Kalisat Jampit adalah 0.55 orang $\mathrm{ha}^{-1}$. Nilai rasio tersebut dapat dikatakan kurang baik karena indeks tenaga kerja (ITK) untuk perkebunan kopi adalah 1.38 orang ha $^{-1}$ (Ditjenbun, 2013). Hasil perbandingan ITK perusahaan dengan norma ITK untuk perkebunan kopi menunjukkan bahwa Kebun Kalisat Jampit kurang efisien dalam menggunakan sumber daya manusia (SDM) dalam proses produksi.

\section{HASIL DAN PEMBAHASAN}

\section{Luas Areal Panen}

Luas panen ditentukan oleh kondisi areal panen dan kondisi tanaman. Kondisi areal panen mempengaruhi pembagian luas panen, di lahan datar pemanenan lebih mudah dan dapat diselesaikan dalam waktu yang lebih singkat dibandingkan dengan lahan berlereng. Kegiatan pemanenan di daerah berlereng membutuhkan waktu yang lebih lama karena kondisi lahan yang sulit dilalui oleh pemetik sehingga pemetik lebih berhati-hati agar tidak jatuh. Kondisi tanaman yang mempengaruhi pembagian luas panen yaitu kerapatan buah yang masak (merah), tinggi tanaman, dan kerapatan tanaman yang berbuah/produktif. Kerapatan buah masak yang tinggi pada setiap pohon di areal panen akan menyebabkan waktu pemanenan lebih lama dibandingkan dengan kerapatan buah masak yang masih sedikit. Pemanenan di blok dengan kerapatan buah masaknya yang rendah, luas panennya akan lebih besar dibandingkan dengan blok yang kerapatan buah masaknya tinggi. Tanaman yang tinggi mempersulit tenaga pemanen melakukan pemanenan, pemetik menggunakan tangga untuk memetik buah pada pohon yang tinggi. Waktu yang dibutuhkan untuk pemanenan di blok dengan kondisi tanaman yang tinggi akan lebih lama dibandingkan dengan blok dengan kondisi tanaman yang rendah. Pemanenan di blok dengan jumlah pohon produktif yang lebih banyak akan membutuhkan waktu pemanenan menjadi lebih lama dibandingkan dengan blok yang jumlah pohon tidak produktifnya lebih banyak. Pemanenan di blok dengan kondisi lahan berlereng, kerapatan buah yang masak, kondisi pohon yang terlalu tinggi, dan jumlah pohon produktif yang tinggi akan memiliki luas panen yang lebih sedikit.

Pembagian luas panen yang dilakukan di Kebun Kalisat Jampit berdasarkan luas dari afdeling dibagi dengan jumlah hari panen dalam satu rotasi (putaran). Jumlah hari pada satu rotasi 8-12 hari, karena maksimal 12 hari, sehingga luas afdeling kebun dibagi menjadi 12 blok panen. Contoh pada Afdeling Kampung Baru, luas afdeling 402.22 ha dengan jumlah putaran panen 12 , sehingga luas panen rata-rata adalah 34 ha hari $^{-1}$, kemudian disesuaikan dengan keadaan tanaman dan keadaan areal kebun. Sebagai contoh adanya perbedaan luas panen pada rotasi-1 (Blok Sabrang dan Panas) dengan rotasi ke-11 (Blok J) disebabkan oleh kondisi areal di Blok Sabrang 
dan Panas yang datar dan mudah dilalui dibandingkan dengan kondisi Blok $J$ yang sebagian besar berlereng (Tabel 2).

Tabel 2. Rotasi pemetik di afdeling Kampung Baru Tahun 2018

\begin{tabular}{llc}
\hline Blok & & \\
Petik & Kebun & Luas (ha) \\
\hline I & Sabrang \& Panas & 27.48 \\
II & Kina & 26.50 \\
III & Selok \& Kina & 27.06 \\
& Pinang dan Mangga & \\
IV & I & 17.50 \\
V & Mangga II \& D & 17.67 \\
& B, Kates, dan & \\
VI & Manting & 20.13 \\
& Manting dan & \\
VII & Bawang & 18.98 \\
VIII & Bawang & 16.79 \\
& Karet dan Sumber & 17.29 \\
IX & Nyonya & 24.00 \\
X & Kendeng & 16.64 \\
XI & J & 17.00 \\
XII & H dan Timur II & 247.04 \\
\hline Jumlah & & \\
\hline Sumber: Kantor Afdeling Kampung Baru
\end{tabular}

Kantor Afdeling Kampung Baru

\section{Tenaga Pemetik}

Hasil t-student menunjukkan bahwa prestasi tenaga kerja pemetik berumur 41-60 tahun lebih tinggi dibandingkan dengan tenaga kerja pemetik berumur 20-40 tahun. Tenaga kerja pemetikberumur 41-60 tahun memetik buah ratarata lebih tinggi, yaitu $28.30 \mathrm{~kg}$ dibandingkan dengan tenaga kerja pemetik berumur 20-40 tahun yang memetik buah rata-rata $24.80 \mathrm{~kg}$ (Tabel 3 ). Menurut Herminingsih dan Hani (2008) pengaruh umur terhadap prestasi petik tidak berkorelasi nyata dengan produktivitas kerja, tetapi berkorelasi nyata dengan pengalaman pemetik. Semakin lama pengalaman pemetik, maka prestasi petik akan semakin tinggi. Hal tersebut disebabkan semakin lama memiliki pengalaman kerja, maka semakin tinggi keterampilan dan prestasi petiknya. Menurut Astuti et al. (2015) tenaga kerja yang memiliki waktu kerja yang sudah lama sebagai pemetik akan memiliki pengalaman yang tinggi sehingga berpengaruh positif terhadap hasil yang diperoleh.

Tabel 3. Pengaruh usia tenaga pemetik terhadap prestasi petik

\begin{tabular}{cccc}
\hline Usia & $\begin{array}{c}\text { Rata-rata } \\
\text { Pemetik }\end{array}$ Prestasi $(\mathrm{kg})$ & Standar Deviasi & $P$-value \\
\hline $20-40$ & 24.8 & 6.45 & \\
$41-60$ & 28.3 & 6.44 & 0.042 \\
\hline
\end{tabular}

Pengamatan pengaruh gender terhadap prestasi petik bertujuan untuk membandingkan prestasi antara tenaga pemetik perempuan dengan prestasi tenaga pemetik laki-laki. Setiap ulangan diambil dari rotasi panen yang berbeda.

Rata-rata prestasi pemetik perempuan dan laki-laki masing-masing sebesar $34.17 \mathrm{~kg}$ dan $34.73 \mathrm{~kg}$ (Tabel 4). Menurut Herminingsih dan Hani (2008) yang mempengaruhi prestasi petik adalah tingkat pengalaman pemetik, semakin tinggi pengalaman maka semakin tinggi prestasi petik.

\section{Alat Panen}

Alat panen yang digunakan di Kebun Kalisat Jampit pada saat pemanenan terdiri atas kocok, sabit, tekote, sapu lidi, garuk, dan tangga (Tabel 5). Kocok merupakan keranjang yang terbuat dari bambu.

Tabel 4. Pengaruh gender terhadap prestasi petik

\begin{tabular}{lclc}
\hline Pemetik & $\begin{array}{c}\text { Rata-rata } \\
\text { Prestasi } \\
(\mathrm{kg})\end{array}$ & $\begin{array}{c}\text { Standar } \\
\text { Deviasi }\end{array}$ & P-value \\
\hline Perempuan & 34.17 & 7.63 & 0.774 \\
Laki-laki & 34.73 & 7.62 & \\
\hline
\end{tabular}

Sabit merupakan celurit yang bentuknya melengkung setengah lingkaran. Tekote merupakan tas yang terbuat dari karung plastik. Garuk merupakakan tongkat pengait yang terbuat dari kayu. Menurut Suwarto et al. (2014) alat yang dibutuhkan dalam pemanenan buah kopi yaitu keranjang bambu atau tas dari daun pandan untuk wadah kopi yang dipetik, karung goni untuk menampung hasil petikan, serta tangga untuk menjangkau tanaman kopi yang tinggi.

\section{Kriteria Buah Kopi yang Dipanen}

Kriteria buah kopi yang dapat dipanen adalah buah berwarna merah (masak penuh), sesuai dengan standar operasional perusahaan. Buah berwarna kuning (bancuk) dan hijau tidaktermasuk kriteria panen, sehingga buah tersebut belum dapat dipanen. Penentuan kriteria buah dapat dipanen bertujuan menjaga kualitas buah yang dipetik yang akan menjadi bahan baku di pabrik pengolahan kopi Arabika di Kebun Kalisat Jampit Cita rasa kopi yang tinggi diperoleh dari kopi glondong yang masak penuh. Menurut Prastowo et al. (2010) hasil biji kopi yang bermutu tinggi diperoleh dari pemetikan buah kopi masak penuh yang ditandai dengan warna kulit buah yang merah merata. Hasil tstudent menunjukkan usia pemetik tidak berbeda nyata terhadapkualitas buah yang dipetik. Tenaga pemetik usia 20-40 tahun tidak berbeda nyata dengan pemetik berumur 41-60 berdasarkan persentase buah merah, buah bancut, dan buah hijau yang dipetik, dengan nilai p-value masingmasing secara berurutan sebesar 0.870, 0.926, dan 0.447 (Tabel 6). 
Tabel 5. Jenis dan kegunaan alat panen di Kebun Kalisat Jampit

\begin{tabular}{|c|c|c|c|}
\hline $\begin{array}{l}\text { Sampel } \\
\text { Pemetik }\end{array}$ & Jenis Alat & Kegunaan Alat & Kondisi Alat \\
\hline 1 & Kocok & Wadah untuk meletakkan glondong merah yang dipetik & baik \\
\hline 2 & Sabit & Alat untuk membersihkan gulma yang mengganggu kegiatan pemanenan & baik \\
\hline 3 & Tekote & Tas/kantong untuk meletakkan glondong hitam/kering & baik \\
\hline 4 & Sapu lidi & $\begin{array}{l}\text { Membersihkan bekas tempat yang digunakan pada kegiatan sortasi dari } \\
\text { kotoran-kotoran sisa panen }\end{array}$ & baik \\
\hline 5 & Garuk & $\begin{array}{l}\text { Alat untuk menjangkau cabang yang terdapat buah kopi masak yang sulit } \\
\text { dijangkau/tinggi }\end{array}$ & baik \\
\hline 6 & Tangga & $\begin{array}{l}\text { Alat yang digunakan pemetik untuk memetik buah kopi pada pohon kopi } \\
\text { yang tinggi }\end{array}$ & baik \\
\hline
\end{tabular}

Tabel 6. Pengaruh usia tenaga pemetik terhadap kualitas hasil dipanen

\begin{tabular}{|c|c|c|c|c|c|}
\hline \multirow[b]{2}{*}{ Kriteria petik } & \multicolumn{2}{|c|}{ Pemetik usia 20-40 tahun } & \multicolumn{2}{|c|}{ Pemetik usia 41-60 tahun } & \multirow[b]{2}{*}{$p$ value } \\
\hline & $\%$ buah & Standar deviasi & $\%$ buah & Standar deviasi & \\
\hline Merah & 66 & 15.70 & 67 & 17.90 & $0.870^{\operatorname{tn}}$ \\
\hline Bancut & 32 & 15.40 & 31 & 8.07 & $0.926^{\mathrm{tn}}$ \\
\hline Hijau & 2 & 1.19 & 2 & 1.18 & $0.447^{\mathrm{tn}}$ \\
\hline
\end{tabular}

Keterangan: $\mathrm{tn}=$ tidak berbeda nyata

\section{Tingkat Kehilangan Hasil (Losses) Saat Pemanenan}

Tingkat kehilangan hasil (losses) pada saat pemanenan mempengaruhi produksi kopi. Hal tersebut akan menyebabkan kerugian bagi perusahaan. Hasil t-student menunjukkan bahwa rata-rata tingkat kehilangan hasil panen di piringan (buah yang jatuh) sebesar 24 buah dengan standar deviasi 18.8, sedangkan rata-rata tingkat kehilangan hasil buah di tajuk (tidak terpetik) sebesar 9 buah dengan standar deviasi 7.04. Hasil $\mathrm{t}$ hitung menunjukkan tingkat kehilangan hasil panen di piringan berbeda nyata dengan tingkat kehilangan hasil panen di tajuk. Tingkat kehilangan buah kopi di piringan lebih besar dibandingkan dengan tingkat kehilangan buah kopi di tajuk (Tabel 7).

Tabel 7. Tingkat kehilangan hasil panen kopi di piringan dan di tajuk

\begin{tabular}{lccc}
\hline Kehilangan & Rata-rata & & \\
Kehilangan & Standar & \\
Buah & Hasil (Buah) & Deviasi & P-value \\
\hline Di piringan & 24.2 & 18.8 & 0.033 \\
Di tajuk & 8.8 & 7.04 & 0.04 \\
\hline
\end{tabular}

Jumlah kehilangan buah yang tertinggal di piringan maksimal yang diizinkan perusahaan berdasarkan standar operasional prosedur (SOP) sebesar 5 buah. Pengamatan dilakukan sebanyak 3 kali ulangan di blok yang berbeda. Hasil uji-t student rata-rata tingkat kehilangan buah di Blok Menara dan Blok Nangka berbeda nyata terhadap SOP petik perusahaan dengan rata-rata buah yang tertinggal di piringan pada masing-masing ulangan adalah 27 dan 24 buah. Sebagian besar buah yang tertinggal adalah buah hijau.
Kehilangan buah di piringan disebabkan oleh gesekan tangga pemetik dengan cabang pohon kopi yang mengakibatkan kerontokan buah kopi, sehingga jatuh dan tertinggal di piringan. Blok Menara dan Blok Nangka merupakan rotasi petik dengan keadaan pohon kopi yang tinggi, berbuah lebat, dan berlereng sehingga kerontokan buah pada saat pemetikan tinggi. Kondisi kebun yang kurang baik/banyak tumbuh gulma menyebabkan pemetik enggan memungut buah yang terjatuh. Kebersihan kebun perlu diperbaiki agar tingkat kehilangan buah dapat dikurangi. Rata-rata tingkat kehilangan buah di Blok KAG tidak berbeda nyata dengan SOP petik perusahaan dengan rata-rata buah yang tertinggal di piringan sebanyak 7 buah. Hal tersebut dapat disebabkan oleh pohon kopi yang tidak tinggi sehingga tidak adanya gesekan antara tangga pemetik dengan pohon kopi. Kondisi areal panen di Blok KAG yang lebih datar dibandingkan dengan di Blok Menara dan Blok Nangka menyebabkan pemetik lebih mudah dalam memungut buah yang terjatuh (Tabel 8).

Tabel 8. Jumlah buah tertinggal di piringan dibandingkan dengan SOP di Kebun Kalisat Jampit

\begin{tabular}{lccc}
\hline Ulangan & $\begin{array}{c}\sum \text { Tanaman } \\
\text { yang } \\
\text { Diamati } \\
\text { (Pohon) }\end{array}$ & $\begin{array}{c}\text { SOP } \\
\text { (Buah) }\end{array}$ & $\begin{array}{c}\sum \text { Buah } \\
\text { Tertinggal } \\
\text { Piringan } \\
\text { (Buah) }\end{array}$ \\
\hline Menara & 10 & 5 & $27^{*}$ \\
Nangka & 10 & 5 & $24^{*}$ \\
KAG & 10 & 5 & \\
\hline KAG
\end{tabular}

Keterangan: * = berbeda nyata pada taraf $5 \%$, tn $=$ tidak berbeda nyata pada taraf $5 \%$ 
Bul. Agrohorti 7(3): 343-350 (2019)

Tabel 9. Rendemen kopi di masing-masing afdeling di Kebun Kalisat Jampit

\begin{tabular}{|c|c|c|c|c|c|c|c|c|c|}
\hline \multirow{2}{*}{ Afdeling } & \multirow{2}{*}{$\begin{array}{l}\text { Jumlah } \\
\text { Glondong } \\
\text { (gram) }\end{array}$} & \multirow{2}{*}{$\begin{array}{l}\text { HS } \\
\text { Pulper } \\
\text { (gram) }\end{array}$} & \multicolumn{2}{|c|}{ HS Normal (gram) } & \multicolumn{2}{|c|}{$\begin{array}{c}\text { Jumlah Rambangan } \\
\text { (gram) }\end{array}$} & \multirow{2}{*}{$\begin{array}{l}\text { Jumlah } \\
\text { Kopi Pasar } \\
\text { (gram) }\end{array}$} & \multirow{2}{*}{$\begin{array}{l}\text { KA } \\
(\%)\end{array}$} & \multirow{2}{*}{$\begin{array}{l}\mathrm{R} \\
(\%)\end{array}$} \\
\hline & & & HS Cuci & HS Kering & HS Cuci & $\begin{array}{c}\mathrm{HS} \\
\text { Kering }\end{array}$ & & & \\
\hline KB & 2000 & 940 & 660 & 252 & 45 & 17 & 269 & 10.5 & 13.5 \\
\hline SP & 2000 & 1120 & 410 & 153 & 90 & 30 & 260 & 10.5 & 13.0 \\
\hline KM & 2000 & 980 & 670 & 278 & 130 & 26 & 276 & 10.5 & 13.8 \\
\hline KP & 2000 & 990 & 720 & 285 & 50 & 5 & 290 & 10.5 & 14.0 \\
\hline JP & 2000 & 990 & 750 & 274 & 50 & 6 & 280 & 10.5 & 14.0 \\
\hline Rata-rata & 2000 & 1004 & 642 & 248.4 & 73 & 16.8 & 275 & 10.5 & 13.7 \\
\hline
\end{tabular}

\section{Rendemen Kopi yang Diperoleh}

Hasil pengamatan rendemen kopi menujukkan rendemen rata-rata di 5 afdeling adalah $13.7 \%$. Nilai rendemen yang rendah disebabkan oleh panen awal. Pada panen awal buah kopi yang dihasilkan tidak sebaik pada panen raya, sehingga rendemen yang dihasilkan pada panen awal lebih rendah. Rendemen tertinggi terdapat di Afdeling Jampit dan Afdeling Krepekan dengan rendemen 14\%, sedangkan rendemen terendah di Afdeling Sempol dengan rendemen 13\% (Tabel 9). Afdeling Jampit dan Afdeling Krepekan memiliki ketinggian tempat yang lebih tinggi. Menurut SOP perusahaan, rendemen biji kopi berkisar $15-17 \%$. Rendemen kopi yang rendah pada pengamatan dapat disebabkan oleh tingginya serangan hama bubuk buah terhadap biji kopi, sehingga menurunkan rendemen kopi.

\section{KESIMPULAN}

Kegiatan pemanenan di Kebun Kalisat Jampit, Bondowoso, Jawa Timur telah dikelola dengan baik, meskipun masih ada beberapa hal yang perlu diperbaiki, yaitu kurangnya pengawasan pada tenaga pemanen yang menyebabkan tingkat kehilangan hasil pada saat pemetikan dan tingginya persentase buah kuning dan hijau yang terpetik. Buah yang jatuh di piringan sangat tinggi melebihi SOP perusahaan. Buah kuning dan hijau yang terpetik sangat tinggi sehingga menurunkan kualitas bahan baku pengolahan di pabrik. Hasil analisis menunjukkan bahwa tingkat kehilangan hasil panen di piringan lebih tinggi dibandingkan di tajuk. Prestasi pemetik usia 41-60 tahun lebih baik dibandingkan pemetik usia 41-60 tahun. Pemetik dengan usia 41-60 tahun memiliki ratarata prestasi yang lebih tinggi dibanding dengan pemetik usia 20-40 tahun.

\section{DAFTAR PUSTAKA}

Afriliana, A. 2018. Teknologi Pengolahan Kopi Terkini. CV Budi Utama, Yogyakarta.

Astuti, W., A. Lubis, Aprollita. 2015. Motivasi dan produktivitas kerja wanita pemetik buah kopi di Desa Serdang Jaya Kecamatan Betara Kabupaten Tanjung Jabung Barat. Sosio Ekonomika Bisnis 18(1):99-110

[Ditjenbun] Direktorat Jenderal Perkebunan. 2013. Pedoman Pelaksanaan Pengelolaan Data Komoditas Perkebunan (PDKP) Edisi Kedua. http//:ditjenbun.pertanian.go.id/ [10 Juli 2018].

[Ditjenbun] Direktorat Jendera Perkebunan 2016. Statistik Perkebunan Indonesia 2015-2017 Kopi. http://ditjenbun.pertanian.go.id/tinym cpuk/gambar/file/satistik/2017/kopi-20152017.pdf [14 Oktober 2017].

Hermaningsih, H., E.S. Hani. 2008. Faktor-faktor yang berkorelasi terhadap produktivitas kerja pemetik kopi di PDP Kabupaten Jember. J-SEP 2(2): 40-46.

Manurung, P., M. Ginting, L. Fauzia. 2016. Strategi peningkatan produksi kopi Arabika (Coffea arabica) (studi kasus: Desa Lumban Silintong, Kecamatan Pagaran, Kabupaten Tapanuli Utara). Jurnal on Social Economic of Agriculture and Agribusiness 5(1): 1-13.

Mayrowani, H. 2013. Kebijakan penyediaan teknologi pascapanen kopi dan masalah pengembangannya. Forum Penelitian Agro Ekonomi 31(1):31-49. 
Najiyati, S., Danarti. 2004. Kopi: Budi Daya \& Penanganan Pascapanen. Penebar Swadaya, Jakarta.

Panggabean, E. 2011. Buku Pintar Kopi. Agromedia Pustaka, Jakarta.

Prastowo, B., E. Karmawati, Rubijo, Siswanto, C. Indrawanto, S.J. Munarso. 2010. Pusat Penelitian dan Pengembangan Perkebunan, Bogor.

Rahardjo, P. 2012. Kopi: Panduan Budi Daya dan Pengolahan Kopi Arabika dan Robusta. Penebar Swadaya, Jakarta.
Saragih, J.R. 2010. Kinerja produksi kopi Arabika dan prakiraan sumbangannya dalam pendapatan wilayah Kabupaten Simalungun. Visi 18(1):98-112.

Sembiring, N.B., I.K. Satriawan, I.A.M. Tuningrat. 2015. Nilai tambah proses pengolahan kopi arabika secara basah (west indischee bereding) dan kering (ost indischee bereding) di Kecamatan Kintamani, Bangli. Jurnal Rekayasa dan Manajemen Agroindustri 3(1):61-72.

Suwarto, Y. Octavianty, S. Haermawati. 2014. Top 15 Tanaman Perkebunan. Penebar Swadaya, Jakarta. 